\title{
O preconceito de classe social no livro didático: um estudo apoiado na Epistemologia Genética
}

\section{Social class prejudice in the textbook: a study based in the Genetic Epistemology}

Ana Carolina Mexia Aleixo ${ }^{1}$, Francismara Neves de Oliveira ${ }^{1 *}$, Guilherme Aparecido Godoi ${ }^{1}$, Silvana Thomas ${ }^{1}$, Sérgio Luís Evangelista de Almeida ${ }^{1}$, Heloisa Braga dos Santos ${ }^{1}$

\section{RESUMO}

Por meio de estudo documental, a pesquisa objetivou identificar situações de preconceito de classe social em textos e imagens de livros didáticos aprovados pelo Programa Nacional do Livro Didático (PNLD) para o $7^{\circ}$ ano do Ensino Fundamental. Tomou por base o aporte da Epistemologia Genética, em especial o estudo da construção moral e considerou o preconceito como resultante de relações interdependentes entre os domínios cognitivo, social e afetivo. Identificou situações reforçadoras do preconceito de classe social relacionados à cor de pele, etnia, acesso à informação, lazer e arte, ambientes sociais frequentados, tipos de trabalho ou profissão, estereótipos históricos e comportamentais. A exemplo, os personagens ricos, cultos e de pele branca, foram retratados frequentando ambientes de lazer, cultura, esporte e informação. Os personagens em situação de pobreza foram retratados com pele preta, em profissões de prestação de serviço e/ou subempregos, ou em temáticas relacionadas à escravidão. Compreende-se que o material analisado se configura como ideológico e reforçador de preconceito de classe social prejudicando a promoção de relações de equidade e desenvolvimento do valor moral do respeito, no contexto escolar.

Palavras-chave: Preconceito de Classe Social; Livro Didático; Desenvolvimento Moral; Epistemologia Genética.

\begin{abstract}
Through a documentary study, the research aimed to identify situations of social class prejudice in texts and images of textbooks approved by the National Textbook Program (PNLD) indicated for 7th elementary school. Based on the contribution of Genetic Epistemology, in particular the study of moral, considered prejudice as resulting from interdependent relations between the cognitive, social and affective domains. Has been identified situations of social class prejudice like as: skin color, ethnicity, access to information, leisure and arts, social environments frequented, types of job, historical and behavioral stereotypes. For example, the rich, cultured and white-skinned characters were portrayed attending leisure, culture, sport and information environments. The characters in poverty were portrayed with black skin, in service or underemployment professions, or in themes related to slavery. In conclusion, the analyzed material is configured as ideological and reinforcer of prejudice of social class hindering the promotion of relations of equity and development of the moral value of respect, in the school context.
\end{abstract}

Keywords: Social Class Prejudice; Textbook; Moral Development; Genetic Epistemology.

\footnotetext{
${ }^{1}$ Universidade Estadual de Londrina - UEL. Londrina, PR, Brasil.

*E-mail: francismara@uel.br
} 


\section{INTRODUÇÃO}

Os aspectos sociais, afetivos e cognitivos nas relações humanas são temas essenciais à área de Psicologia da Educação, à Educação e às áreas afins que se dedicam à temática do desenvolvimento humano. Tal compreensão favorece a elaboração de programas de intervenção pedagógica compatíveis às demandas próprias de cada ciclo da aprendizagem escolar. A presente pesquisa é apoiada na teoria piagetiana ou Epistemologia Genética. Nessa perspectiva, o desenvolvimento cognitivo, social e afetivo é fruto de construções interdependentes (OLIVEIRA; GODOI, 2018; REIS, 2020; GONÇALVES, 2022). Assim, no contexto interacionista, a moralidade é uma construção social que decorre das relações interdependentes e se apresenta nas atitudes e comportamentos dos sujeitos (PIAGET, 1994; THOMAS, 2020).

Os comportamentos apresentados por crianças, adolescentes, jovens, adultos e idosos, refletem tais construções à medida em que o pensamento e os sentimentos morais evocados nas interações sociais são organizados internamente e devolvidos em resposta ao meio externo. A noção social que se destaca é o preconceito e em especial o preconceito de classe social, que corresponde ao tratamento de pessoas de modo discriminado pela situação econômica, nível de escolaridade, acesso à renda, bens e serviços. Este tipo de preconceito é manifesto por comportamentos relacionados à intolerância, hostilidade, implicância, perseguição, repúdio, exclusão, entre muitos outros conceitos cabíveis, em que há um juízo de valor preconcebido sobre algo ou alguém que se ancora em uma opinião construída sem fundamento, conhecimento nem reflexão, ou seja, um prejulgamento. O preconceito de classe social está inclinado à valorização maior de classes sociais economicamente privilegiadas e a discriminação de sujeitos menos favorecidos (GONÇALVES; OLIVEIRA, 2019; GONÇALVES, 2022).

Ao tratar da questão do preconceito de classes sociais, no campo da moralidade na teoria piagetiana, é importante citar os tipos de moralidade: anomia, heteronomia e autonomia. Gonçalves e Oliveira (2019) apresentam uma síntese das discussões de Piaget (1994) que diferenciam os tipos morais: A anomia é um período Pré-Moral, cujas características se evidenciam até por volta de 2 ou 3 aproximadamente. Na Heteronomia ou Moralidade Heterônoma, preponderante até por volta de 9-10 anos, o interesse da criança volta-se à participação de atividades coletivas e regradas. Neste caso, sendo ainda influenciada pela percepção concreta da realidade (pensamento pré-operatório e 
operatório concreto), age conforme um Realismo Moral de uma lei severa, rígida e infalível, o que seria percebido de forma concreta, em que a obediência se daria por via da coação. Sendo ainda egocêntrica, as regras são tomadas como prioridades sem consultar os interesses ou perspectivas de outros sujeitos, em vista de um benefício próprio. No entanto, ocorre que ela ainda não teria se tornado capaz de compreender as relações entre objetos da realidade (incluindo ela e os outros) e por isso não conseguiria compreender como o outro se relaciona com ela, o que sente e pensa, pois, para isso será necessário superar o egocentrismo. Na Autonomia ou Moralidade Autônoma, há presença de uma concepção adulta de jogo e de relacionamento. A partir dos 10-11 anos, a criança/pré-adolescente pode aceitar, respeitar e seguir as regras por meio da cooperação e em virtude do amadurecimento do pensamento operatório formal e suas estruturas. A regra passaria a ser compreendida como acordo mútuo entre os dirigentes, e de fato, mais flexível e modificável conforme as circunstâncias, e conforme indica o pensamento hipotético. Desse modo, o Realismo Moral - egocentrismo, regra concreta e absoluta seria assim superado pela Norma da Reciprocidade, caracterizada pela superação do egocentrismo, uma regra relativa e produto da vontade coletiva.

Ressalta-se na teoria piagetiana que identificar a predominância da heteronomia ou autonomia em dada fase do desenvolvimento não significa que ela seja extinta na fase subsequente. Por isso falamos de predomínio de um tipo ou outro de moralidade. Os tipos de moral heterônoma e autônoma subsistem e coexistem ao longo de todo desenvolvimento (PIAGET, 1994; TOGNETTA; LA TAILLE, 2008).

A moralidade autônoma ou heterônoma resulta diretamente nos modos de pensar a realidade social, garantindo maior ou menor condição do exercício da democracia. (LA TAILLE, 1992, 1994, 2006, 2019). Assim, a interação social, a equilibração (construções internas autorreguladas), as aprendizagens e as experiências ativas do sujeito em adaptação ao meio permitem que organize a si mesmo e ao ambiente externo mutuamente e, embora seja uma construção interna, está submetido às interações com o objeto.

Partindo desse entendimento, a escola possui o papel de exercer a democracia em todas as instâncias a fim de partilhar em suas interações, ambientes igualmente democráticos, favorecedores de discussão, de argumentação, aceitação de diferentes pontos de vista e incentivo à contestação de opiniões com justificativas de posicionamentos (MONTOYA, 2013; VINHA; TOGNETTA, 2009). 
Atrelado aos tipos predominantes de moralidade, se manifestam dois tipos de respeito, como discorrem Alves (2019), Menin (2019): o respeito unilateral e o respeito mútuo. No respeito unilateral, ocorre o respeito em uma obediência por via da autoridade, como por exemplo de filhos com os pais. No entanto, o respeito mútuo (autonomia) tem sua origem do unilateral (heteronomia) e se dá quando a criança tem uma visão de que é como o outro, se colocando no lugar e mediando as suas próprias ações de controle no comportamento, e não se prende ao princípio de autoridade estabelecido no período anterior.

Em conformidade com tais apontamentos, o presente artigo buscou responder aos seguintes questionamentos: Quais situações de preconceito de classe social são encontradas no material didático do $7^{\circ}$ ano do Ensino Fundamental II e quais as vinculações da noção de preconceito e estereótipo aos tipos de moral?

Assim, para este estudo objetivou-se 1) Identificar no material didático situações que reforçam estereótipos e preconceitos; 2) Discutir as situações de preconceito de classe social comparando-as à moralidade heterônoma e autônoma descritas na perspectiva teórica; 3) Reconhecer no material aspectos relativos à construção do conhecimento social do preconceito de classes e compreender os sentidos produzidos pelo livro didático em ambiente escolar.

\section{PROGRAMA NACIONAL DO LIVRO DIDÁTICO}

Em 1998, os Parâmetros Curriculares Nacionais - PCNs (BRASIL, 1998) deliberaram sobre as Diretrizes Nacionais Curriculares (BRASIL, 2013) que norteiam a educação brasileira para o trabalho realizado em sala, e assim como as influências dos PCNs, o Programa Nacional do Livro Didático - PNLD (BRASIL, 1985) que foi criado para avaliar os livros didáticos, de forma a garantir que eles pudessem "atender às necessidades do professor, do aluno e da escola, com diversidade de teorias educacionais e pedagógicas, além de levar em consideração as diretrizes dos órgãos nacionais, estaduais e municipais de educação" (BRASIL, 2007, p. 9).

O PNLD é o responsável por avaliar e disponibilizar as obras didáticas, pedagógicas e literárias entre outros materiais de prática educativa, possui caráter sistemático, regular e gratuito direcionado às escolas públicas de educação básica e instituições de educação infantil comunitárias, confessionais ou filantrópicas por meio do 
poder público sem interesses lucrativos. A compra e a distribuição dos materiais selecionados pelo Ministério da Educação no domínio da Secretaria de Educação Básica (SEB) são responsabilidade do Fundo Nacional de Desenvolvimento da Educação (FNDE), bem como a disponibilização e alteração necessárias dos materiais para as escolas públicas do país cadastradas no censo escolar. O MEC não distribui o material de maneira avulsa ao público e não possui versão para download das obras.

Nas competências gerais da Educação Básica, a BNCC reconhece que a Educação deve fornecer a formação e o desenvolvimento humano global, a fim de compreender quão complexo é esse processo, rompendo com

visões reducionistas que privilegiam ou a dimensão intelectual (cognitiva) ou a dimensão afetiva [...] significa, ainda, assumir uma visão plural, singular e integral da criança, do adolescente, do jovem e do adulto - considerando-os como sujeitos de aprendizagem - e promover uma educação voltada ao seu acolhimento, reconhecimento e desenvolvimento pleno, nas suas singularidades e diversidades (BRASIL, 2018, p. 14).

Assim, nos documentos oficiais (BRASIL, 2018) compreende-se como essencial o desenvolvimento da empatia, do diálogo, da resolução de conflitos e a cooperação, em busca do respeito mútuo e direitos humanos, com acolhimento e valorização da diversidade dos sujeitos e grupos sociais em seus saberes, identidades, culturas e potencialidades, sem preconceitos de qualquer natureza.

Além das competências que são fundamentais às práticas escolares e pedagógicas, o PNLD ao basear-se na BNCC indica considerar esses componentes no material didático como um espaço de aprendizagem e democracia inclusiva, evitando qualquer discriminação, preconceito e promovendo reflexões acerca do respeito às diferenças e diversidades.

\section{ASPECTOS METODOLÓGICOS}

A pesquisa é de abordagem qualitativa e caracterizada como análise documental. Tomou como aporte a Epistemologia Genética de Jean Piaget e analisou a proposição de conteúdos e imagens dos livros avaliados pelo PNLD na identificação de preconceito e em especial do preconceito social, estereótipos e padrões sociais. Foram analisados livros do $7^{\circ}$ ano do Ensino Fundamental indicados para uso nas escolas estaduais de um 
município paranaense, nas seguintes disciplinas: História, Geografia, Matemática, Inglês e Projetos Integradores. $\mathrm{O} 7^{\circ}$ ano foi escolhido por conveniência de acesso aos pesquisadores.

\section{RESULTADOS E DISCUSSÃO}

O conteúdo dos materiais escolares deve identificar as formas de produção dos preconceitos, compreender seus efeitos e combater posicionamentos discriminatórios, bem como problematizar "preconceitos e estereótipos relacionados ao universo das lutas e demais práticas corporais, propondo alternativas para superá-los, com base na solidariedade, na justiça, na equidade e no respeito" (BRASIL, 2018, p. 235).

Assim, a construção de valores

[...] vincula-se aos conhecimentos originados em discussões e vivências no contexto da tematização das práticas corporais, que possibilitam a aprendizagem de valores e normas voltadas ao exercício da cidadania em prol de uma sociedade democrática. A BNCC se concentra mais especificamente na construção de valores relativos ao respeito às diferenças e no combate aos preconceitos de qualquer natureza. Ainda assim, não se pretende propor o tratamento apenas desses valores, ou fazê-lo só em determinadas etapas do componente, mas assegurar a superação de estereótipos e preconceitos expressos nas práticas corporais (BRASIL, 2018. p. 221).

Partindo dessa perspectiva, a pesquisa identificou que, para além das propostas de discussão e conscientização existem diversas situações fortalecedoras do respeito unilateral por valores sobre os quais o pensamento preconceituoso é edificado, com manifestação de egocentrismo, de indiferença à perspectiva alheia, como se revela a moralidade heterônoma. Além do preconceito de classe presente no material, foi possível elencar mais categorias de preconceito: de cor, etnia, acesso à informação e arte, acesso a ambientes sociais, estereótipos de trabalho, estereótipos históricos e comportamentais em que os sujeitos típicos, mais abastados e de cor branca apareciam em diversos ambientes de lazer, cultura, esporte e informação em sua grande maioria, enquanto, os sujeitos atípicos, com deficiências, de determinados traços históricos, de cor de pele preta não eram encontrados, ou, apareciam em sua grande maioria em ambientes de trabalho, serviço, contextos históricos ligados à escravidão, ou subempregos. 
No Quadro 1 estão reunidos alguns livros didáticos, seus respectivos autores e editoras, e as observações extraídas (personagens, ações e/ou textos) as quais são representativas para o favorecimento de um ideário do preconceito de classes.

Quadro 1 - Identificação de preconceito textuais e de imagens no material didático

\begin{tabular}{|c|c|c|}
\hline LIVRO & EDITORA & DESCRIÇÃO: PERSONAGENS/ AÇÕES/ TEXTOS \\
\hline $\begin{array}{l}\text { Ciências } \\
\text { CARNEVALLE } \\
(2018)\end{array}$ & Moderna & $\begin{array}{l}\text { 1) Representação de um menino negro retirando água do poço } \\
\text { (p. 240) } \\
\text { 2) Representação de um menino de pele branca na folha anterior } \\
\text { em uma competição de esporte de corrida (p. 238) } \\
\text { 3) Representação de um menino de pele branca em um } \\
\text { campeonato de aviões de papel (p. 187) } \\
\text { 4) Representação de criança branca nadando na piscina (p. 206) }\end{array}$ \\
\hline $\begin{array}{l}\text { Geografia } \\
\text { DELLORE (2018) }\end{array}$ & Moderna & $\begin{array}{l}\text { 5) Representação de uma mulher baiana cozinhando e mostrando } \\
\text { as influências de costumes e tradições do povo iorubá (p. 78) } \\
\text { Frase do livro "[...] a luta atual desses povos é para que sejam } \\
\text { socialmente incluídos e que suas terras sejam reconhecidas e } \\
\text { preservadas" (p. 78) }\end{array}$ \\
\hline $\begin{array}{l}\text { História } \\
\text { BOULOS (2018) }\end{array}$ & FTD & $\begin{array}{l}\text { 6) Texto "Os escravizados" (p. 173-175) } \\
\text { 7) Representação de imagem com título "Mulher nobre com sua } \\
\text { escrava negra" (p. 145) } \\
\text { escrate }\end{array}$ \\
\hline $\begin{array}{l}\text { Inglês } \\
\text { FRANCO; } \\
\text { TAVARES (2018) }\end{array}$ & Editora Ática & $\begin{array}{l}\text { 8) Representação de uma família de cor branca com } \\
\text { equipamentos, andando de bicicleta em um passeio (p. 188) } \\
\text { 9) Pessoas com deficiência: atletas paraolímpicos em competição } \\
\text { de corrida (p. 42) }\end{array}$ \\
\hline
\end{tabular}




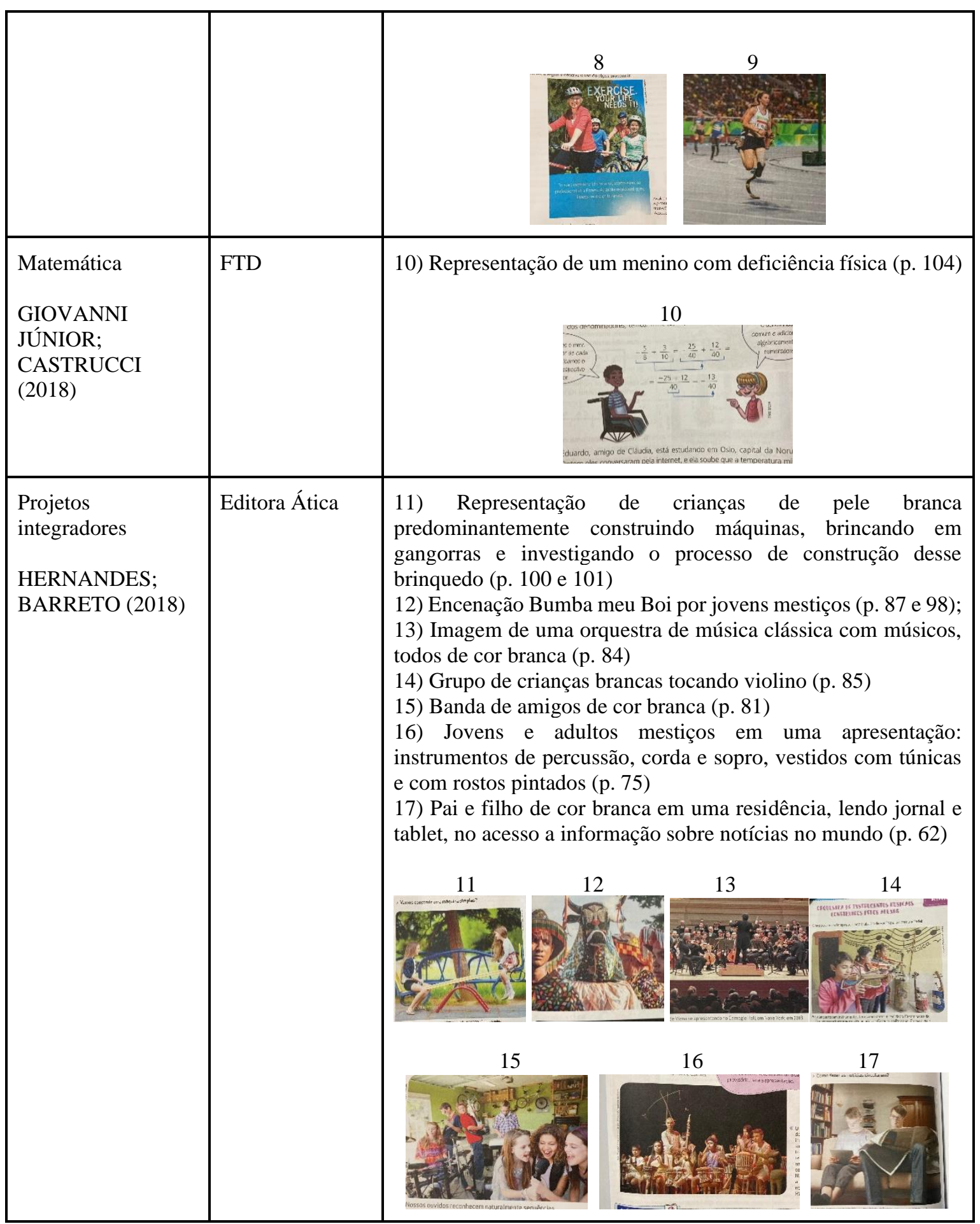

Fonte: dados do estudo

A análise dos excertos selecionados evoca diferentes temas relevantes à discussão acerca do preconceito: gênero, raça, religião, lugares sociais que engendram as expressões culturais e os lugares de pertencimento em nosso contexto de interações. A questão que emerge desse conjunto de imagens e textos do material didático, além daquilo que já foi explicitado como nefasto, é que o preconceito de classe social só pode ser percebido por 
meio de uma análise mais cuidadosa, pela sua sutileza porque surge oculto nas demais formas de preconceito já anunciadas. A crítica aqui estabelecida é sobre a ausência da representatividade das diversidades nos ambientes sociais, a estereotipização que anula sujeitos, os padrões que regulam o pertencimento, os preconceitos que empobrecem as relações e invisibilizam os sujeitos.

Como indicado no Quadro 1, no material de Ciências observou-se imagens de um menino de cor de pele preta retirando água de um poço, enquanto outro menino de cor de pele branca estava saindo da piscina. Ainda outro menino de pele branca participando de uma competição de avião em um aeroporto e outro, na praia. Evidencia-se nesta análise, a falta de representatividade de pessoas de todas as cores, gênero e etnias em todos os lugares de acesso ao lazer.

Por sua vez, no livro de Geografia trouxe a representação de uma mulher baiana cozinhando e mostrando as influências de costumes e tradições do povo Iorubá. Logo após, há uma frase que discorre sobre as lutas desse povo na busca de inclusão e preservação de suas terras, porém, não há no livro evidências de questões que gerem reflexão acerca do papel da população não Iorubá, na superação do preconceito e da exclusão, o que acaba evidenciando esse estereótipo racial e circunscrevendo a luta contra o preconceito a quem o sofre. Embora nessa obra seja possível observar a diversidade distribuída, mais que nos demais livros analisados, ainda assim, há ausência de proposição de discussão e aprofundamento sobre o papel da sociedade diante de acontecimentos históricos, para além da simples descrição.

No livro de História, no texto "Os escravizados" foi observada ausência de questões norteadoras para discutir em âmbitos morais a questão do preconceito. Relatouse apenas questões sobre as posses de terra, matéria-prima, capitanias, engenhos, localizações, entre outros temas correspondentes ao assunto. Assim como a imagem intitulada como "Mulher nobre e sua escrava negra", que não apresentou reflexão e questões sobre a temática da mulher escravizada, apenas contendo explicação sobre as características das sociedades hispano-americanas (chapetones, criollos, mestiços, indígenas e negros escravizados), sem reflexão sobre o preconceito e sua relação com a atualidade.

No livro de História aparecem questões de escravidão, de sofrimentos, sobre a África em sua grande maioria em texto e imagens estereotipadas pela pobreza, sofrimento e dificuldades alimentares. Foram encontradas poucas referências ou quase nenhuma de 
africanos como grandes músicos, escritores, chefes, ou em imagens relativas a lugares e paisagens belíssimas que esse continente possui, ou ainda sobre a vida econômica, cultural, religiosa e política. No entanto, algumas questões importantes para refletir são: Onde estão essas pessoas representadas também no acesso à informação, ao lazer, aos passeios, viagens e acesso à informação? E pessoas atípicas? Por que não as representar também com uma maior proporção no livro de projetos integradores?

No material de Inglês, houve a representação de uma família de cor branca andando de bicicleta em um passeio. Foi possível identificar imagens e situações de pessoas de pele branca em sua grande maioria tendo acesso a passeios, ambientes de lazer, de estudos, enquanto as pessoas de pele preta encontradas em sua grande maioria prestando serviços, lavando roupas e pratos e em alguns poucos ambientes escolares. Há ainda, fotos de pessoas com deficiência competindo em paraolimpíadas na corrida. Fica evidente a carência de representatividade de mais pessoas com deficiência, considerando que se estivessem nas imagens, textos, histórias, profissões, entre outros aspectos, em diversos lugares e realidades, em livros variados, promoveria maior pertencimento e representação.

Por sua vez, no livro de Matemática também aparece um menino com deficiência e o personagem é representado com sua amiga para resolver um problema matemático. Ou seja, a imagem é evocada para dizer que há representatividade, mas não há nada que faça alusão ao respeito e sim ao conteúdo matemático apenas. Em suma, fica apenas a cargo do professor evocar discussão a partir da imagem de duas crianças em atividade conjunta, sendo que uma delas apresenta uma deficiência. A imagem por si só não pe garantia de discussão em sala de aula. A possibilidade de superação do preconceito pelo desenvolvimento da noção de respeito mútuo continua ausente.

Por fim, o livro relativo à disciplina denominada Projetos Integrados trouxe representações de crianças de pele branca investigando a construção de máquinas e brinquedos, como por exemplo, a brincadeira com gangorras; imagem de uma orquestra de música clássica com músicos, todos de cor branca; grupo de crianças brancas tocando violino; pai e filho de cor branca em uma residência, lendo jornal e tablet no acesso à informação sobre notícias no mundo; banda de amigos de cor branca tocando instrumentos e cantando e alguns outros jovens, de pele cor preta ou mestiços em encenações apenas do Bumba meu boi. Em outro momento também jovens e adultos 
mestiços em uma apresentação com instrumentos de percussão, corda e sopro, vestidos com túnicas e com rostos pintados.

Assim, observa-se em maior quantidade um padrão de imagens estereotipados, pois enquanto sujeitos de cor branca eram representados com instrumentos musicais em diversas bandas, com amigos, em atividades de lazer, criando projetos, com acesso à informação e educação, em momentos de lazer familiar, os sujeitos de pele preta ou mestiços apareciam somente em expressões artísticas específicas, históricas e estereotipadas que embora importantes, apresentam-se acríticas.

Como descreve Chimamanda (2009) essas histórias fazem parte de quem cada um deles são, independentemente de suas objetividades, no entanto não se deve apresentar apenas um lado da história nesses materiais, pois, inserir apenas as partes negativas ou só positivas de um povo é superficializar sua experiência e negligenciar as muitas outras histórias em que fazem parte.

Uma única história contada cria estereótipos e a desumanidade estabelecida nos estereótipos evidenciam incompletude, prejulgamento, superficialidade, e tornam a história uma única visão de mundo. O diálogo crítico-reflexivo é condição para gerar pertencimento, representatividade, pertencimento, respeito mútuo, superando o respeito unilateral, por meio da forma como as histórias e relatos são contados.

\section{CONSIDERAÇÕES FINAIS}

Conclusivamente inferiu-se que apesar dos avanços dos processos avaliativos e discussões anunciadas no próprio edital e no programa (PNLD), foi possível identificar ausência de uma abordagem crítica ao material escolhido para o trabalho nas escolas públicas, no que concerne ao preconceito. O PNLD apresentou discurso de conformidade a BNCC e, embora haja nos documentos oficiais alusão à necessidade de romper com as formas de preconceito e discutir em sala de aula esses temas, o próprio material fornecido como base para o trabalho pedagógico apresenta estruturação preconceituosa, referendado por políticas públicas educacionais, por meio de seus editais.

Foram identificadas situações de preconceito no material indicado para o trabalho com os adolescentes, desde aqueles relacionadas à etnia e cor de pele até aos mais sutis, de classe e acesso aos recursos e serviços disponíveis socialmente. Compreende-se que o material analisado se configura como ideológico e reforçador de situações de preconceito 
de classe social e demais instâncias, em flagrante ruptura com as pesquisas sobre o desenvolvimento humano que se dedicam a pensar a escola como ambiente propício à extinção de preconceitos e à promoção de respeito mútuo. Houve poucas pessoas representadas cultural, étnica, biológica e socialmente considerando fisionomias, especificidades entre muitos outros aspectos fundamentais em pauta, como acesso a automóveis, ao lazer, às profissões não estereotipadas para pessoas pretas e pobres.

Assim, o presente artigo abriu um espaço para a reflexão acerca da produção e seleção de materiais didáticos e práticas pedagógicas escolares favorecedoras de ambiente político e socio democrático. Ressaltou a importância de se identificar a ideologia implícita no material e a base teórica que o norteia, visando oferecer a construção de relações de tolerância e flexibilidade, favorecedoras de conflito cognitivo, responsáveis pela superação de preconceito nas relações e respeito mútuo, a fim de favorecer a representatividade e as diversidades presentes na sociedade.

O material para que possa gerar conflito cognitivo, deve compor o ambiente político de debate sobre as questões da sociedade, não invisibilizando sujeitos e suas demandas sociais. Além disso, deve ser informativo, levar reflexões sobre os dilemas da sociedade promovendo transformação. O processo de desconstrução de estereótipos, rótulos, padrões, paradigmas, pode ser desencadeado por meio da leitura, das discussões das imagens e da representatividade, favorecendo nova leitura do mundo, dos sujeitos e de si mesmos.

\section{REFERÊNCIAS}

ALVES, Rebeca M. P. A Construção da Moralidade na Educação Infantil: em busca de autonomia e respeito nas relações interpares. 2019.74 folhas. Trabalho de Conclusão de Curso (Graduação em Pedagogia) - Universidade Estadual de Londrina, Londrina, 2015.

BOULOS, Alfredo. História, Sociedade e Cidadania. (Ensino Fundamental) PNLD. FNDE. 4. ed. SP: FTD, 2018.

BRASIL. Programa Nacional do Livro Didático. Fundo Nacional de Desenvolvimento da Educação, Secretaria de Ensino Fundamental. Brasília: MEC/SEF, 1985. disponível em: $<$ http://portal.mec.gov.br/component/content/article?id=12391:pnld > acesso em: $14 / 01 / 2022$

BRASIL. Parâmetros Curriculares Nacionais. Secretaria de Ensino Fundamental. Brasília: MEC/SEF, 1998. 
BRASIL. Guia de livros didáticos PNLD 2008: Geografia (Anos Finais do Ensino Fundamental) / Ministério da Educação. Brasília: MEC, 2007. disponível em < http://portal.mec.gov.br/seb/arquivos/pdf/Avalmat/pnldgeog07.pdf $>$ acesso em $14 / 01 / 2022$

BRASIL. Diretrizes Curriculares Nacionais Gerais da Educação Básica. Secretaria de Educação Básica. Brasília: MEC/SEB, DICEI, 2013.

BRASIL. Ministério da Educação. Base Nacional Comum Curricular, 2018.

CARNEVALLE, Maíra R. Araribá mais: Ciências. (Ensino Fundamental). PNLD. FNDE. 1. ed. SP: Moderna, 2018.

CHIMAMANDA, Adichie. O perigo de uma única história. 2009. disponível em < https://www.ted.com/talks/chimamanda_adichie_the_danger_of_a_single_story/transcri pt?la nguage $=$ pt-br $>$ acesso em 14/01/2022

DELLORE, Cesar B. Araribá mais: Geografia. (Ensino Fundamental) PNLD. FNDE. 1. ed. SP: Moderna, 2018.

FRANCO, Claudio; TAVARES, Kátia. Way to english: For Brazilian learners. (Ensino Fundamental) PNLD. FNDE. 2. ed. SP: Editora Ática, 2018.

GIOVANNI JÚNIOR, José R. CASTRUCCI, Benedicto. A conquista da matemática (Ensino Fundamental) PNLD. FNDE. 4. ed. SP: FTD, 2018.

GONÇALVES, Carlos E. S; OLIVEIRA, Francismara. N. Dimensões intelectual e afetiva do juízo moral de estudantes sobre manifestações de preconceito. Schème Revista Eletrônica de Psicologia e Epistemologia Genéticas, vol.11 (2), 2019.

GONÇALVES, Carlos E. S. Preconceito de classe social nas significações de estudantes de ensino técnico: um estudo embasado no aporte teórico da Epistemologia Genética. Tese (Doutorado em Educação). Universidade Estadual de Londrina. UEL, 2022. 403 fls.

HERNANDES, Roberta; BARRETO, Ricardo G. Da escola para o mundo. (Ensino Fundamental) PNLD. FNDE. 1. ed. SP: Editora Ática, 2018.

LA TAILLE, Yves. de. et al. Construção da fronteira da intimidade: a humilhação e a vergonha na educação moral. Cadernos de Pesquisa, São Paulo, n. 82, p. 43-55, 1992.

LA TAILLE, Yves. de. A dimensão ética na obra de Jean Piaget. Idéias, São Paulo, n. 20, p. 75-82, 1994.

LA TAILLE, Yves. de. Moral e ética: dimensões intelectuais e afetivas. Porto Alegre: Artmed, 2006.

LA TAILLE, Yves. de. Moral e contemporaneidade. Revista Eletrônica de Psicologia e Epistemologia Genética, Marília, v. 11, n. Especial, p. 6-24, 2019. 
MENIN, Maria. S. D. S. Adesão a valores sociomorais na contemporaneidade: um estudo com escolares de ensino fundamental e médio. Revista Eletrônica de Psicologia e Epistemologia Genética, Marília, v. 11, n. Especial, p. 86-122, 2019.

MONTOYA, Adrián O. D. Realidade, Conhecimento Físico e Conhecimento Social: Processos e Mecanismos Comuns de Construção. Schème-Revista Eletrônica de Psicologia e Epistemologia Genéticas, v. 5, p. 40-64, 2013.

OLIVEIRA, Francismara N.; GODOI, Guilherme A.; Noções de Espaço e Lugar na perspectiva de alunos o $6^{\circ}$ Ano do Ensino Fundamental II: relações de interdependência entre conhecimento social e cognitivo. Ensino Em Re-Vista, Uberlândia, v.25, n. 1, p. 134-158, jan./abr. 2018.

PIAGET, Jean. O Juízo moral na criança. Tad. Elzon Lenardon - São Paulo: Summus, 1994.

PIAGET, Jean. Relações entre a afetividade e a inteligência no desenvolvimento mental da criança. Tradução de Cláudio J. P. Saltini e Doralice B. Cavenaghi. Rio de Janeiro: Wak, 2014.

REIS, Leandro.A. dos. Músico na sala de aula ou professor no palco? Processos de sinificações de licenciandos nas dimensões do músico e professor - encontros possíveis. Tese (doutorado em educação). Universidade Estaduald e Londrina - UEL, 2020., 192 fls.

THOMAS, Silvana. Significações de vergonha e erro em alunos do Ensino Médio dimensões cognitivas, afetivas e sociais: um estudo à luz da epistemologia genética. 2020. 91 f. Dissertação (Mestrado em Educação) - Universidade Estadual de Londrina, Londrina, 2020.

TOGNETTA, Luciene. R. P.; LA TAILLE, Yves. de. A formação de personalidades éticas: representações de si e moral. Psicologia: Teoria e Pesquisa, Brasília, v. 24, n. 2 , p. 181-188, 2008.

VINHA, Telma. P.; TOGNETTA, Luciene. R. P. Construindo a autonomia moral na escola: os conflitos interpessoais e a aprendizagem dos valores. Revista Diálogo Educacional, Curitiba, v. 9, n. 28, p. 525-540, set./dez. 2009. 